\title{
Modulation of duodenal iron uptake by hypoxia and fasting in the rat
}

\author{
BY E. M. TAYLOR*, K. B. RAJA, R. J. SIMPSON† AND T. J. PETERS \\ Department of Clinical Biochemistry, King's College School of Medicine and Dentistry, Bessemer Rd, \\ London SE5 9PJ
}

(Received 6 November 1995 - Revised 11 June 1996 - Accepted 14 June 1996)

\begin{abstract}
The effect of hypoxic exposure on in vitro duodenal Fe uptake kinetics was studied in tissue fragments from rats that were fed or fasted overnight before study. Hypoxic exposure was for $3 \mathrm{~d}$ at $0.5 \mathrm{~atm}$ and fasting was for the last 18-24 h before Fe uptake determinations. The non-permeable $\mathrm{Fe}^{2+}$ chelator 3-(2-pyridyl)-5,6-bis-(4-phenyl-sulphonic acid)-1,2,4-triazine (ferrozine), and medium deoxygenation inhibited uptake in all experimental groups. Ferrozine sensitivity and mucosal $\mathrm{Fe}^{3+}$ reductase activity were greatest in hypoxic animals. Fe uptake was inhibited by membrane depolarization only after fasting or hypoxic exposure of the rats. The data demonstrated that Fe uptake by rat duodenal fragments involves at least two mechanisms: a membrane-potentialindependent mechanism which is not responsive to hypoxia and a second mechanism, induced by fasting or hypoxia, which is inhibited by membrane depolarization. Uptake is partially dependent on reduction of $\mathrm{Fe}^{3+}$ to $\mathrm{Fe}^{2+}$ and this is primarily associated with the second mechanism for uptake. These properties have been reported also in mouse and human Fe uptake, suggesting that the rat is a useful model for the study of basic mechanisms of Fe absorption.
\end{abstract}

Iron: Intestine: Membrane potential

Transport studies with in vitro model systems have been of key importance in the elucidation of the mechanisms of intestinal absorption of nutrients, for example, glucose (Bihler \& Crane, 1962). We have developed and validated for Fe-uptake studies the in vitroincubated intestinal fragment system (Cox \& Peters, 1979; Raja et al. 1987b). This system is of particular value in the study of the initial uptake step for $\mathrm{Fe}$ absorption, which probably represents the key site for the interaction of mucosal and dietary factors for the determination of $\mathrm{Fe}$ absorption. Determination of mucosal Fe uptake kinetics by incubating intestinal fragments in vitro has been applied extensively to mice (Raja et al. 1987a) and human subjects (Cox \& Peters, 1979, 1980). Such studies have led to hypotheses concerning the defect in human haemochromatosis (Cox \& Peters, 1980), a membrane-potential dependence of mouse duodenal Fe uptake (Raja et al. 1989) and a requirement for reduction of $\mathrm{Fe}^{3+}$ to $\mathrm{Fe}^{2+}$ before uptake by mouse (Raja et al. 1992) and human duodenum (Raja et al. 1996). Recently, attempts have been made to extend the membrane potential and reduction hypotheses to the rat (O'Riordan et al. 1994; Wein \& Van Campen, 1994), the most-frequently-used small-animal model for Fe nutrition studies. It is of key interest to test whether the duodenal uptake of Fe by this species shows similar properties to those observed in the mouse and human subjects. In the present study we have investigated the interaction between modulators of $\mathrm{Fe}$ absorption, i.e. chronic hypoxia and fasting, in

\footnotetext{
*Present addreas: Department of Neuroscience, School of Medicine, Center for Molecular Genetics, UCSD, La Jolla, CA, USA.

†For reprints.
} 
determining Fe uptake. This was achieved by exposing rats to normoxic or hypoxic conditions for $3 \mathrm{~d}$ with or without feeding on the last day. The role of reduction and membrane potential in the uptake process was studied in rats subjected to these various treatments.

\section{MATERIALS AND METHODS}

\section{Animals}

Male Wistar rats ( $n$ 180) were obtained from an out-bred colony maintained in the Comparative Biology Unit at King's College School of Medicine and Dentistry. They were maintained on a common chow (Diet CRM; supplied by Special Diet Services, Witham, Essex) from weaning. This chow contained $106 \mathrm{mg} \mathrm{Fe} / \mathrm{kg}$ diet (manufacturer's data) and was provided, together with tap water ad libitum throughout the study, except as indicated below. The procedure was approved by the UK Home Office. At the start of each procedure animals were 6-8 weeks old and weighed 250 (SE 10) g. Rats were housed in plastic and stainless-steel grid-bottomed cages (two to three per cage). Rats were weighed at the time of receipt and the time of killing. Rats were exposed to a normal cycle of $12 \mathrm{~h}$ light and $12 \mathrm{~h}$ darkness in a temperature-controlled room held at $21^{\circ}$. All animals were killed within 1 week of receipt. Two types of experiment were performed. In one experiment, the effect of hypoxia and fasting on a number of variables, i.e. Fe uptake with or without membrane depolarization, Fe-uptake kinetics, mucosal free fatty acid levels, mucosal reductase activity or $\mathrm{Fe}$ uptake in the presence or absence in the medium of ferrozine was determined. This required several studies as only one or two variables could be determined in a single study. This was achieved by randomly assigning rats to four groups of four to eight animals, i.e. normoxic fed (control), normoxic fasted, hypoxic fed and hypoxic fasted. The latter two groups were exposed to chronic hypoxia by placing animals in a hypobaric chamber set at $0.5 \mathrm{~atm}(53.3 \mathrm{kPa})$ for $3 \mathrm{~d}$. Such treatment simulates an altitude of approximately $5000 \mathrm{~m}$ above sea level and has been shown to stimulate $\mathrm{Fe}$ absorption in rats (Osterloh $\boldsymbol{e t}$ al. 1987). The two fasted groups were allowed water but denied food for 18-24 $\mathrm{h}$ before killing. At the end of the treatments animals were killed in a randomized order and used for studying in vitro $\mathrm{Fe}$ uptake or mucosal free fatty acid levels as described on pp. 461-463. The number of animals used for each treatment in a given study is detailed with the results. The second type of experiment involved varying the time of hypoxic exposure. Batches of up to eight rats were placed in the hypobaric chamber and groups of two to three rats were removed after various times of exposure. Normoxic controls were studied in parallel. Up to four cages (eight rats) were housed in the hypobaric chamber at any one time, including both fed and fasted animals. The hypobaric chamber was not large enough to house metabolic cages, thus food spillage is included in values for food consumption. Food was generally absent from the duodenum of all animals at the time of death. Fasted animals had little or no food in the stomach or small intestine. Fed animals generally did not eat after daylight on the day of study; however they still had food in their stomach at the time of killing.

\section{Materials}

Reagents were purchased at the highest appropriate grade from Merck Ltd (Lutterworth, Leics.) except L-ascorbate, EDTA, 4-(2-hydroxyethyl)-1-piperazine-ethanesulphonic acid (HEPES), nitrilotriacetic acid (NTA), 2,2', $2^{\prime \prime}$-nitrilotriethanol (triethanolamine), palmitic acid, phloridzin and 3-(2-pyridyl)-5,6-bis-(4-phenyl-sulphonic acid)-1,2,4-triazine (ferro- 
zine) which were obtained from Sigma Chemical Company Ltd (Poole, Dorset); Metophane (methoxyfluorane) from C-Vet (Bury St Edmunds, Suffolk); Ecolume scintillation fluid from ICN Biomedicals Inc., (High Wycombe, Bucks.); Lumatom tissue solubilizer from Hans Kurner Analysen Technik (Brude-Grimm-Strasse, 6 Postfach, Germany); cyanocobalamin (Cytamen injection BP) from Duncan Flockhart and Co. Ltd (Uxbridge, Middlesex) and 1,5-diphenyl carbazide which was obtained from Aldrich Chemical Company Ltd (Gillingham, Kent).

${ }^{59} \mathrm{Fe}$ as $\mathrm{FeCl}_{3}$ was supplied by NEN-Dupont (Stevenage, Herts.) or Amersham International Plc (Aylesbury, Bucks.); $0.5 \mathrm{mCi}$ of NEN-Dupont ${ }^{59} \mathrm{Fe}(5-75 \mathrm{Ci} / \mathrm{g}$ ) was supplied in $100 \mu \mathrm{l} 0.5 \mathrm{M}-\mathrm{HCl}$ and was diluted $1: 4(\mathrm{v} / \mathrm{v})$ with $10 \mathrm{mM}-\mathrm{HCl}$ immediately on delivery while ${ }^{59} \mathrm{Fe}(3-50 \mathrm{Ci} / \mathrm{g}$ from Amersham International $\mathrm{Plc})$ was supplied in $1 \mathrm{ml}$ $0.1 \mathrm{M}-\mathrm{HCl}$. Before use $100 \mu \mathrm{Ci}$ of either stock was diluted to a volume of $0.5 \mathrm{ml}$ with $10 \mathrm{mM}-\mathrm{HCl}$. $\left[{ }^{57} \mathrm{Co}\right]$ cyanocobalamin was supplied by Amerlite Diagnostics Services Ltd (Amersham, Bucks.) in $10 \mu \mathrm{Ci}$ portions $(0.014-0.027 \mathrm{mCi} / \mathrm{nmol} ; 0.5-1.0 \mathrm{MBq} / \mathrm{nmol})$ in benzyl alcohol $(9 \mathrm{ml} / \mathrm{l}){ }^{51} \mathrm{Cr}$ EDTA was supplied by Amersham International Plc (Health Care Division) as a $1: 1$ complex of EDTA with chromic ion in an aqueous solution containing benzyl alcohol $(10 \mathrm{ml} / \mathrm{l} ; 1-2 \mathrm{mCi} / \mathrm{mg})$. Methyl $\left(\alpha-\mathrm{D}-\left[\mathrm{U}-{ }^{14} \mathrm{C}\right]\right.$ gluco)-pyranoside (50-200 $\mathrm{mCi} / \mathrm{mmol}$ ) was supplied by Amersham International $\mathrm{Plc}$ as a solution in aqueous ethanol $(30 \mathrm{ml} / 1)$.

\section{${ }^{59} \mathrm{Fe}$ uptake by duodenal fragments}

The in vitro method for measuring ${ }^{59} \mathrm{Fe}$ uptake by intestinal fragments was based on that described by Cox \& Peters (1979) and Raja et al. (1987b). Rats were anaesthetized with Metophane and bled by cardiac puncture. A portion $(5 \mu \mathrm{l})$ of non-heparinized blood was immediately taken into $1 \mathrm{ml}$ Drabkin's reagent for measurement of haemoglobin levels (see p. 462).

Rats were then killed by cervical dislocation and approximately $20 \mathrm{~mm}$ of the duodenum, immediately distal to the bile duct, was removed. The piece of intestine was opened longitudinally and then cut into small pieces of 3-15 mg wet weight. The fragments (up to twenty per animal) were washed by gentle vortex-mixing in HEPES medium, at room temperature (to remove any adhering food particles and mucus) and then pre-incubated for approximately $1 \mathrm{~min}$ at $37^{\circ}$ in HEPES medium containing $5 \mathrm{nM}$ cyanocobalamin. The fragments were then transferred to a second tube containing a medium with ${ }^{59} \mathrm{Fe}$ and ${ }^{57} \mathrm{Co}$ at $37^{\circ}$. Fe uptake was terminated after $5 \mathrm{~min}$ by lightly blotting the pieces of gut and vortexing them for $3 \mathrm{~s}$ in ice-cold HEPES medium. This washing time has been shown by Raja et al. (1987a) to remove non-specifically-bound radioactivity. The wet weight of the fragments was recorded before counting individual fragments for ${ }^{59} \mathrm{Fe}$ and ${ }^{57} \mathrm{Co}$, simultaneously, for $1 \mathrm{~min}$ in a gamma-counter (LKB-Wallac $1282 \mathrm{Compu}-$ gamma; LKB-Wallac, Helsinki, Finland). Within-animal CV values were found to be in the range $<25 \%$, while between-animal CV values were generally $>25 \%$. Uptake values for fragments from a given animal (four to six fragments for given treatment and incubation conditions) were, therefore, averaged and the average taken as the uptake value; $n$ values refer to the number of these averaged values.

In experiments where the ferri-reductase activity of the gut fragments was investigated, the fragments were transferred from the pre-incubation medium into the radioactive medium together with $100 \mathrm{mM}$-ferrozine $(100: 1, \mathrm{v} / \mathrm{v})$. A $100 \mu \mathrm{l}$ portion of the medium was immediately taken ( $t 0 \mathrm{~min}$ ) and added to $400 \mu$ ldeionized water. Further portions were taken at 1, 2, 3, and $5 \mathrm{~min}$. After $5 \mathrm{~min}$ incubation the fragments were blotted, rinsed, 
weighed and counted. As ferrozine forms a purple complex with $\mathrm{Fe}^{2+}$, the rate of $\mathrm{Fe}^{3+}$ reduction can be determined by spectrophotometric measurement $(562 \mathrm{~nm})$ of colour formation in the incubation media. After measuring the absorbance of the diluted $100 \mu \mathrm{l}$ portions of incubation medium, the Fe in these portions was fully reduced by addition of excess ascorbic acid and the absorbance measured. This measurement provided a standard with which to relate the absorbance in the portions of medium to the amount of Fe reduced.

\section{${ }^{59}$ Fe uptake by gut sacs}

To determine the effective contributions to overall fragment uptake by the mucosal and serosal surfaces, the uptake of $\mathrm{Fe}^{3+}$ by 'right-side out' and everted gut sacs was investigated. After anaesthetization of animals with Metophane and subsequent cervical dislocation, approximately $100 \mathrm{~mm}$ of the duodenum (immediately distal to the bile duct) was removed, rinsed through with $100 \mathrm{ml}$ HEPES medium and divided into two pieces. One of these was everted over a plastic rod. The location of the portion of gut taken for evertion was alternated between sequential replicates within experimental groups. Both pieces were then filled with HEPES medium (to prevent the sacs floating) and each tied-off with surgical thread into two closed sacs, which were then separated from each other using a scalpel. The everted sacs were well rinsed and blotted to remove mucus. The four sacs were then pre-incubated in oxygenated HEPES medium for approximately $1 \mathrm{~min}$ at $37^{\circ}$. After this time interval they were incubated for $5 \mathrm{~min}$ in $5 \mathrm{ml}$ oxygenated radioactive medium at $37^{\circ}$. Sacs were removed from the incubation media, blotted and thoroughly rinsed with ice-cold HEPES medium. The sacs were blotted again and the ends cut off, inside the ligatures, in order to prevent counting of radioactivity adsorbed to the surgical thread. 'Right-side out' sacs were cut open and the inside thoroughly blotted to remove mucus, ensuring that wet weights were comparable with those of the everted sacs. Sacs were weighed and ${ }^{59} \mathrm{Fe}$ and ${ }^{57} \mathrm{Co}$ counted for 1 min using a LKB-Wallac 1282 Compugamma gamma-counter.

\section{$\mathrm{Na}^{+}$-dependent glucose uptake by fragments}

Duodenal fragments were prepared as described previously and then up to twenty were preincubated in oxygenated HEPES medium at $37^{\circ}$ for approximately $1 \mathrm{~min}$ before placing them (four to six fragments from a single animal in a given incubation medium) in HEPES medium containing $50 \mathrm{mM}$-methyl- $\alpha$-glucopyranoside; the $\mathrm{pH}$ was adjusted with $1 \mathrm{M}$-Tris to $7 \cdot 3$. $\left[{ }^{14} \mathrm{C}\right]$ Methyl glucopyranoside $(1 \cdot 8-2.2 \mathrm{mCi} / \mathrm{ml})$ was added in trace amounts and ${ }^{51} \mathrm{Cr}$ EDTA $(0.8-1.2 \mathrm{mCi} / \mathrm{ml})$ was used as an extracellular-fluid marker. For the $\mathrm{Na}^{+}$-free medium, $\mathrm{NaCl}$ was replaced with choline chloride, and for the phloridzin-containing medium the inhibitor was included at $1 \mathrm{mM}$. After incubation for $5 \mathrm{~min}$ the fragments were removed, blotted and rinsed. After weighing and ${ }^{51} \mathrm{Cr}$ counting, the fragments were placed in $\beta$-counting vials with $200 \mu \mathrm{l}$ Lumatom tissue solubilizer. The vials were left overnight to allow complete digestion of the tissue before addition of $5 \mathrm{ml}$ Ecolume scintillant, then counted on a LKB-Wallac 1214 Rackbeta Spectral liquid scintillation counter.

\section{Biochemical assays}

Haemoglobin was determined by adding a $5 \mu \mathrm{l}$ portion of freshly collected, nonheparinized, blood to $1 \mathrm{ml}$ Drabkin's solution (Drabkin \& Austin, 1932), mixing and recording absorption at $540 \mathrm{~nm}$. 
For the purpose of performing precise kinetic determinations, the Fe concentration of radioactive stocks was determined spectrophotometrically using ferrozine. The procedure used was adapted from the colour-reaction step in the non-haem-Fe assay of Foy et al. (1967). Standards contained 1 and $2 \mathrm{nmol} \mathrm{FeCl}$.

\section{Mucosal free fatty acid levels}

Animals were anaesthetized and then killed by cervical dislocation. Approximately $100 \mathrm{~mm}$ of the duodenum distal to the bile duct was removed and immediately rinsed through with $50 \mathrm{ml}$ ice-cold $0.15 \mathrm{M}-\mathrm{NaCl}$. This has been shown to stop effectively the formation of free fatty acids in the isolated tissue (Simpson et al. 1989). All instruments and equipment that came in contact with tissue thereafter were ice-cold. The gut was cut open and the mucosa scraped off with a microscope slide. The serosa was discarded and the mucosa homogenized in $5 \mathrm{ml}$ ice-cold HEPES medium in a Dounce homogenizer. A $50 \mu \mathrm{l}$ portion of the homogenate was transferred to a stoppered glass tube containing $6 \mathrm{ml}$ chloroform-heptane $(1: 1, \mathrm{v} / \mathrm{v})$ with methanol $(20 \mathrm{ml} / \mathrm{l})$ and $1 \mathrm{ml} \mathrm{KH}_{2} \mathrm{PO}_{4}(33 \mathrm{mM})-$ $\mathrm{Na}_{2} \mathrm{HPO}_{4}(33 \mathrm{mM} ; 2: 1, \mathrm{v} / \mathrm{v})$ and shaken for $90 \mathrm{~s}$. The remaining homogenate was transferred to a $30 \mathrm{ml}$ vial and incubated at $37^{\circ}$ for up to $120 \mathrm{~min}$. At intervals, further portions were taken into organic mix. Free fatty acid concentrations were determined in the extracts as described by Falholt et al. (1973). A standard curve was constructed from palmitic acid over the range $0-2 \mathrm{mM}$.

\section{Data analysis and statistical methods}

All data from investigations of the concentration dependence of $\mathrm{Fe}^{3+}$ uptake were fitted to the Michaelis-Menten equation for a single-binding site using the direct linear plot method of Eisenthal \& Cornish-Bowden (1974). Two types of statistical analysis were performed on the data. Where only one comparison was involved (i.e. between one control and one test group) the Student's $t$ test was used (paired or unpaired as appropriate). In cases where multiple comparisons were to be made, two-way or three-way ANOVA was performed using the general linear model (Minitab Inc., 1992). Where appropriate, multiple comparison of means was performed, following ANOVA, by the Student-Newman-Keuls test for all pairwise comparisons (Glantz \& Slinker, 1990). The threshold for significance was set at $P<0.05$.

\section{RESULTS}

\section{Tissue viability}

Viability of duodenal fragments was demonstrated by uptake of the glucose analogue $\left[{ }^{14} \mathrm{C}\right]$ methyl- $\alpha$-glucopyranoside. This uptake was significantly inhibited by replacement of $\mathrm{NaCl}$ with choline chloride (44\% inhibition; $P<0.001$ ) and by the inclusion of $1 \mathrm{mM}$ phloridzin in the incubation medium (98\% inhibition; $P<0.001)$. These results demonstrate the uptake of methyl-glucopyranoside by the $\mathrm{Na}^{+}$-dependent glucose transporter, thus indicating the functional viability of fragments. In addition, examination of gut morphology after 5 min incubation in $450 \mu \mathrm{M}-\mathrm{Fe}^{3+}-\mathrm{NTA}(1: 2, \mathrm{v} / \mathrm{v})$ at $37^{\circ}$ showed that rat duodenal tissue remains intact under these conditions. These results agree with those of Raja et al. $(1987 b, 1989)$ and, hence, there is good evidence to suggest that duodenal fragments from the rat are functionally viable for the duration of the experiments presented here. 


\section{${ }^{59}$ Fe uptake by duodenal fragments}

There was a good correlation between fragment weight and ${ }^{59} \mathrm{Fe}^{3+}$ uptake $(r 0.95)$ and between weight and $\left[{ }^{57} \mathrm{Co}\right]$ cyanocobalamin (extracellular-fluid marker) uptake ( $r$ 0.93). However, ${ }^{59} \mathrm{Fe}$ was associated with fragments in excess of $\left[{ }^{57} \mathrm{Co}\right] \mathrm{cyanocobalamin}$ and this indicates that the association is not entirely due to the extracellular-fluid space. The uptake of ${ }^{59} \mathrm{Fe}$, after correction for the extracellular fluid and extrapolation to zero fragment size, was not significantly different from zero. This indicates that the cut surfaces of the fragments did not contribute significantly to the uptake of ${ }^{59} \mathrm{Fe}$.

Everted and 'right-side out' gut sacs were used to investigate the contribution, to total fragment uptake, of uptake through the serosal surface. The combined uptake via the serosal and mucosal surfaces in these sac experiments approximated to the uptake values ( $\mathrm{pmol} / \mathrm{mg}$ wet weight per $\mathrm{min}$ ) seen in fragments from fed $(n 13$; sacs 5.04 (SE 0.24) $v$. fragments 7.5 (SE 3.3)) and for fasted animals ( $n$ 5; sacs 6.21 (SE 0.61) v. fragments 9.3 (SE 4.2)). The data show that the total uptake increased significantly $(P<0.05)$ in fasted animals. This increase was accompanied by a marginally significant increase $(P=0.0553)$ in mucosal uptake (uptake by everted sacs), without any change in the serosal uptake in fasted animals. In normoxic animals, serosal uptake comprised approximately 45 and $41 \%$ of the uptake in fed and fasted animals respectively.

\section{Effect of hypoxia and fasting on animal weight and haemoglobin levels}

The effect of fasting and/or hypoxia on haemoglobin levels is shown in Table 1. There were significant main effects of both fasting and hypoxia on haemoglobin and body weight $(P<0.001)$. Fasting, exposure to hypoxia, and the combination of hypoxia and fasting caused an increase in haemoglobin levels.

It was found that during the first day of exposure to hypoxia the food consumption of the rats used here was reduced by two-thirds; animals ate 4.4 (SE 0.8$) \mathrm{g}(n$ 7) compared with the normal rate of $15 \mathrm{~g} / \mathrm{d}$. Feeding was back to normal by the second day (14.4 (SE $0.4) \mathrm{g} ; n$ ) and remained so on the third day (16.9 (SE 1.5$) \mathrm{g} ; n$ ). The decrease in food consumption seen on day 1 of hypoxic exposure was reflected in a decrease in the body weight of hypoxic animals as compared with normoxic fed animals (Table 1). As expected a decrease in body weight was also seen in animals which had been fasted for 18-24 h before the experiments and in animals which had been exposed to $3 \mathrm{~d}$ of hypoxia with fasting over the last $24 \mathrm{~h}$.

\section{Effect of fasting, hypoxia and membrane depolarization on ${ }^{59} \mathrm{Fe}$ uptake}

Preliminary in vitro studies in fed rats showed that Fe uptake was not affected by membrane depolarization and 3 d hypoxia caused only a small increase in Fe uptake. This is in contrast to the effect of hypoxia on intestinal Fe uptake in mice. It was thought that the differing responses in mice and rats to hypoxia may be due to differences in food intake; it has been shown that the rates of feeding in mice are decreased over the entire $3 \mathrm{~d}$ of hypoxic exposure (R. J. Simpson, unpublished results). To test this hypothesis the effect of fasting and hypoxia on Fe uptake was investigated (Table 1). Fasting of normoxic animals (i.e. normoxic fasted) caused a small increase in Fe uptake and, as seen in the hypoxic fed animals, uptake was inhibited $(35 \%)$ in high- $\mathrm{K}^{+}$solutions (Fig. 1). Fasting of hypoxic animals, over the last 18-24 h of exposure to hypoxia, caused a 2-4-fold increase in $\mathrm{Fe}^{3+}$ uptake and this uptake was decreased by approximately $42 \%$ in a high- $\mathrm{K}^{+}$medium. Threeway ANOVA indicated that there was a significant effect of hypoxia, fasting and of high- 
Table 1. Effect of hypoxia and fasting on body weight, haemoglobin levels and kinetic variables of $\mathrm{Fe}^{3+}$ uptake by duodenal fragments from rats $\dagger$

(Mean values with their standard errors for nos. of rats shown)

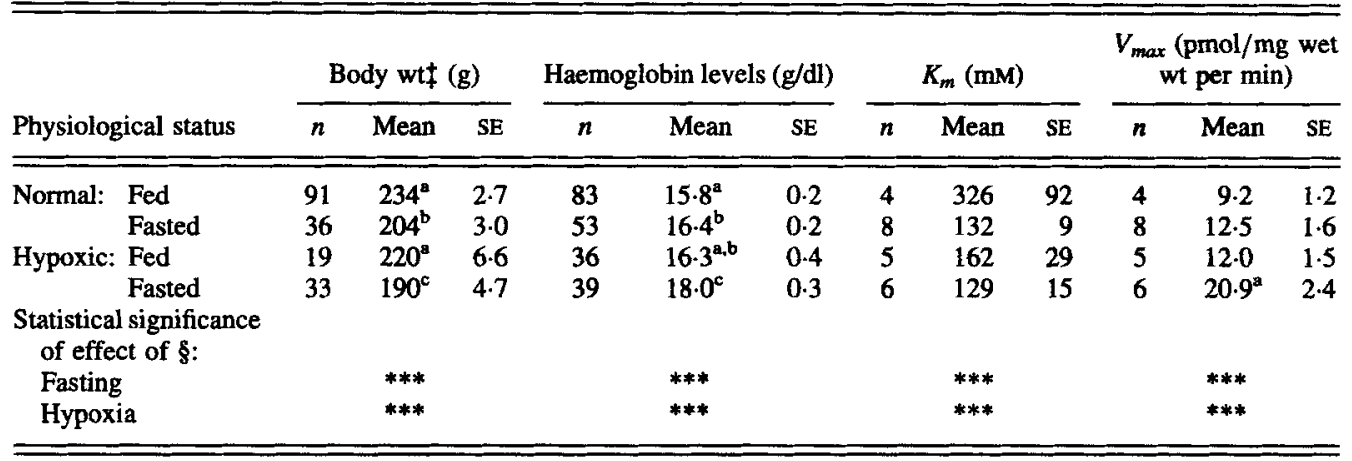

a,b,c Mean values in columns with unlike superscript letters were significantly different $(P<0.05)$.

$* * * P<0.001$.

†For details of animals and procedures, see pp. 460-463.

$\ddagger$ At the time of killing.

§Two-way ANOVA.

$\mathrm{K}^{+}$buffer $\left(P<0.001\right.$ in all cases) on $\mathrm{Fe}^{3+}$ uptake. Subsidiary tests suggested that there was no significant increase in uptake by normoxic fasted and hypoxic fed animals as compared with normoxic fed. However, there was a significant increase in uptake in hypoxic fasted animals as compared with the other three animal groups. In the presence of high- $\mathrm{K}^{+}$ medium, there were, no significant differences between groups. The decrease in uptake seen when fragments from hypoxic fed or hypoxic fasted animals were incubated in high $\mathrm{K}^{+}$is significant. These data suggest that both fasting and hypoxia induces a $\mathrm{K}^{+}$-sensitive (i.e. membrane-potential-dependent) uptake mechanism.

\section{Time-course of hypoxic response}

To further investigate the hypoxic response of $\mathrm{Fe}^{3+}$ uptake, the time dependence of the response in fed animals was investigated. Fig. 2 shows the results of the present study. As previously shown, there was no significant increase in Fe uptake by duodenal fragments from fed animals after $3 \mathrm{~d}$ of hypoxia; there was, however, a significant inhibition of uptake when fragments were incubated in high- $\mathrm{K}^{+}$solution. Fig. 2 shows that the effect is evident after $1 \mathrm{~d}$ of hypoxia. Two-way ANOVA showed that there were significant effects of both duration of hypoxic exposure $(P<0.001)$ and of high-K $\mathrm{K}^{+}$buffer $(P<0.001)$ on Fe uptake. In addition there was a significant interaction between duration of hypoxic exposure and the buffer $(P<0.001)$. Subsidiary tests suggested that uptake was not significantly increased after 1,2 or $3 \mathrm{~d}$ of hypoxia compared with normoxic fed animals. Uptake by tissue from normoxic fed animals was unaffected by high $\mathrm{K}^{+}$, but uptake was significantly inhibited by membrane depolarization in tissue from animals exposed to hypoxia for $1(41 \%), 2(48 \%)$ or $3(45 \%) \mathrm{d}$. The data show that the sensitivity to membrane depolarization developed on the first day of hypoxic exposure. 


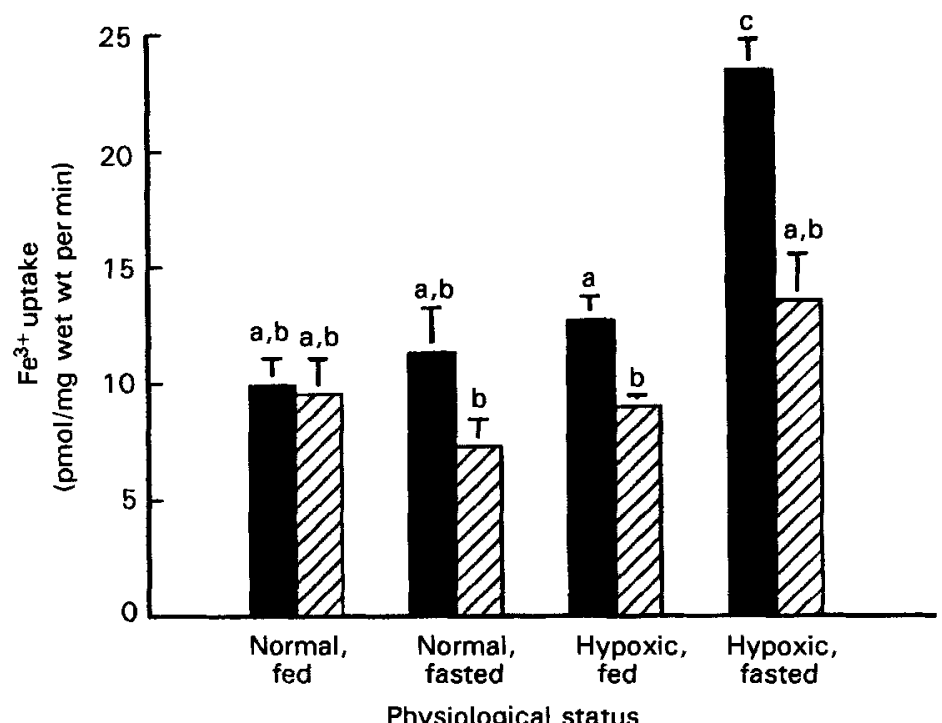

Fig. 1. Effect of hypoxia and fasting on $\mathrm{Fe}^{3+}$ uptake in duodenal fragments from rats. Duodenal fragments were prepared from normal fed, normal fasted, hypoxic fed or hypoxic fasted animals and incubated in normal 4-(2hydroxyethyl)-1-piperazine ethanesulphonic acid medium $(\square)$ or in medium containing a high $\mathrm{K}^{+}$concentration $(\square)$. Each solution contained $450 \mathrm{mM}-{ }^{59} \mathrm{Fe}^{3+}$ in $900 \mathrm{mM}$-nitrilotriacetic acid and included $\left[{ }^{57} \mathrm{Co}\right]$ cyanocobalamin as an extracellular-fluid marker. Values are means with their standard errors represented by vertical bars for seven to eight rats. ${ }^{2, b, c}$ Mean values with unlike superscript letters were significantly different $(P<0.05)$. For details of animals and procedures, see pp. $460-463$.

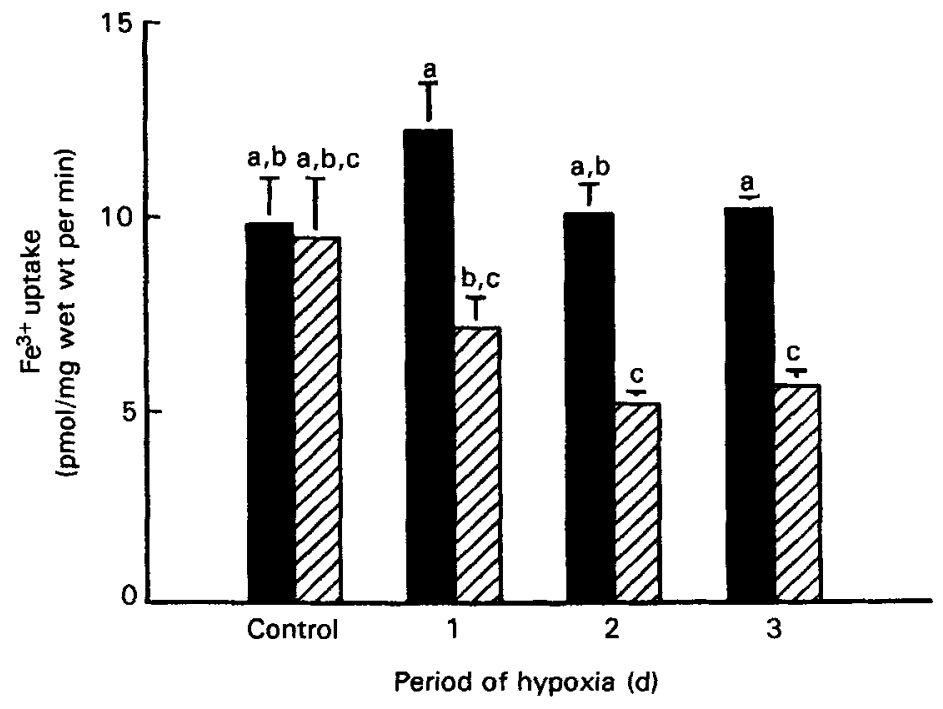

Fig. 2. Time-course of $\mathrm{Fe}^{3+}$ uptake response to hypoxia in duodenal fragments from fed rats. Duodenal fragments were prepared from normal fed animals and from animals exposed to hypoxia for 1,2 or $3 \mathrm{~d}$. Uptake of Fe $\mathrm{From}^{3+}$ $450 \mathrm{mM}^{59} \mathrm{Fe}^{3+}$ in $900 \mathrm{mM}$-nitrilotriacetic acid was measured after 5 min incubation at $37^{\circ}$ in normal 4-(2hydroxyethyl)-1-piperazine ethane sulphonic acid medium ( $\square$ ) or medium containing a high $\mathrm{K}^{+}$concentration (ख); $\left[{ }^{57} \mathrm{Co}\right]$ cyanocobalamin was the extracellular-fluid marker. Values are means with their standard errors represented by vertical bars for six rats. Mean values with different superscript letters were significantly different $(P<0$.05). For details of animals and procedures, see pp. 460-463. 


\section{Kinetics of ${ }^{59} \mathrm{Fe}$ uptake by rat duodenum}

The uptake of $\mathrm{Fe}^{3+}$ by duodenal fragments from all four groups of animals was linear over 10 min at both 450 and $45 \mu \mathrm{M}$. Fig. 3 shows the concentration dependence of $\mathrm{Fe}^{3+}$ uptake in normoxic fed, normoxic fasted, hypoxic fed and hypoxic fasted animals. The data from each group could be fitted by the Michaelis-Menten equation for a single binding site and the $V_{\max }$ and $K_{m}$ were calculated for each group (Table 1). There was a significant effect of both hypoxia and fasting on the $K_{m}$ for $\mathrm{Fe}^{3+}$ uptake. The $K_{m}$ was decreased in normoxic fasted, hypoxic fed and hypoxic fasted animals compared with that for normoxic fed animals. The $V_{\max }$ for $\mathrm{Fe}^{3+}$ uptake by fragments was increased in normoxic fasted, hypoxic fed and hypoxic fasted animals compared with normoxic fed rats. Two-way ANOVA indicated that there was a significant effect of hypoxia $(P<0.001)$ and of fasting $(P<0.001)$ on the $V_{\max }$ for $\mathrm{Fe}^{3+}$ uptake. These data suggest that a low $K_{m}$ mechanism of uptake is induced by hypoxia and fasting.

\section{Contribution of media components to uptake characteristics}

There was no significant change in the rate of uptake in any of the animal groups when glucose was omitted from the medium. This suggests that the inhibition in Fe uptake by replacement of medium $\mathrm{Na}^{+}$with $\mathrm{K}^{+}$is not due to effects on glucose uptake. When fragments from any of the animal groups were incubated without oxygenation, uptake was significantly decreased $(P<0.001 ; 31 \%$ for both normoxic fed and normoxic fasted and $21 \%$ and $22 \%$ for hypoxic fed and hypoxic fasted respectively; not shown). It has been shown in the mouse that removal of $\mathrm{Ca}^{2+}$ from the media causes an increase in uptake (Raja et al. 1987c). It has been suggested that this is due to an increase in the stability of the

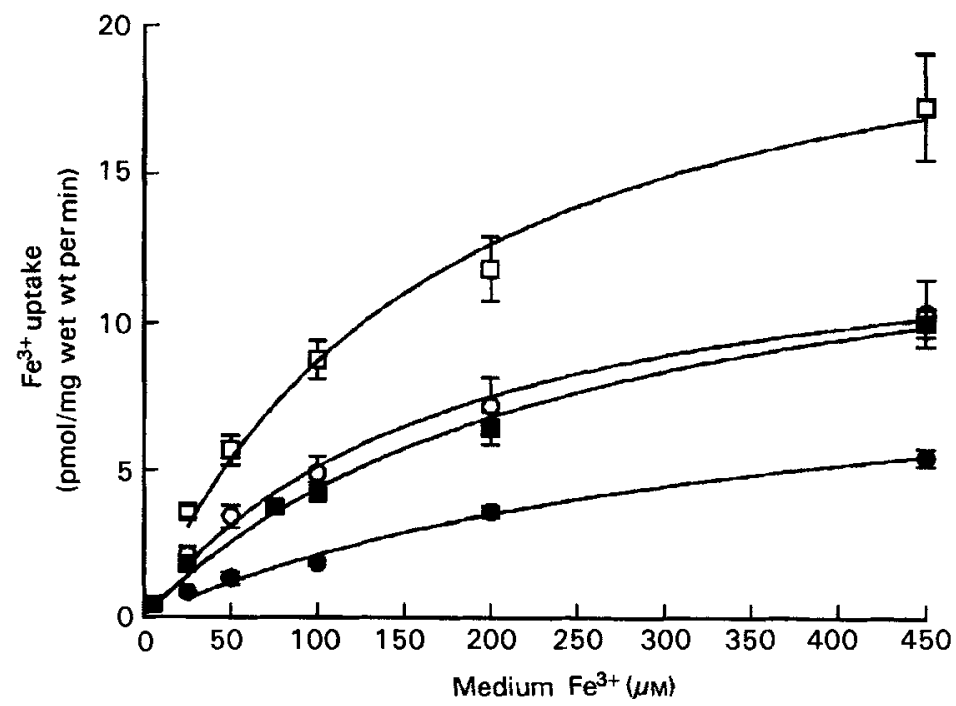

Fig. 3. Kinetics of $\mathrm{Fe}^{3+}$ uptake by duodenal fragments from rats. Concentration dependence of $\mathrm{Fe}^{3+}$ uptake from $450 \mathrm{~mm}-{ }^{59} \mathrm{Fe}^{3+}-900 \mathrm{mM}$-nitrilotriacetic acid was studied in fragments prepared from normal fed ( $($ ), normal fasted $(0)$, hypoxic fed $(\square)$ and hypoxic fasted animals $(\square)$. Fragments were incubated for 5 min at $37^{\circ}$ in $4-(2-$ hydroxyethyl)-1-piperazine ethane sulphonic acid medium containing $5-450 \mathrm{mM}-{ }^{59} \mathrm{Fe}^{3+} ;\left[{ }^{57} \mathrm{Co}\right] \mathrm{cyanocobalamin}$ was added to the medium as an extracellular-fluid marker. The Michaelis-Menten equation was fitted to each set of data; values for $K_{m}$ and $V_{\max }$ are shown in Table 1. Values are means with their standard errors represented for vertical bars for four to eight rats. 
$\mathrm{Fe}^{3+}-\mathrm{NTA}$ complex. We found that $\mathrm{Ca}^{2+}$ caused no significant change in the levels of uptake in rat fragments in any animal group (values not shown).

Reductase activity and effect of $\mathrm{Fe}^{2+}$ chelation on $\mathrm{Fe}^{3+}$ uptake by fragments

It has been suggested recently that a mucosal ferri-reductase plays a central role in the specific uptake of $\mathrm{Fe}^{3+}$ in the mouse duodenum (Raja et al. 1992). It was, therefore, of interest to investigate the role of reduction in the uptake of $\mathrm{Fe}$ from $\mathrm{Fe}^{3+}-\mathrm{NTA}$ by rat duodenum. Table 2 shows the effect, on $\mathrm{Fe}^{3+}$ uptake, of including $1 \mathrm{mM}$-ferrozine in the incubation medium; ferrozine is a specific $\mathrm{Fe}^{2 f}$ chelator which would rapidly bind any $\mathrm{Fe}^{2+}$ produced. In all four animal groups the presence of the $\mathrm{Fe}^{2+}$ chelator decreased $\mathrm{Fe}^{3+}$ uptake significantly $(P<0.001$; three-way ANOVA). There was also a significant interaction between the effect of hypoxia and ferrozine in the medium. Subsidiary tests suggest that there was a significant increase in uptake in normoxic fasted, hypoxic fed and hypoxic fasted animals as compared with normoxic fed animals. There was a further significant increase in uptake in hypoxic fasted animals as compared with all other animal groups. There were no significant differences in uptake between groups in the presence of ferrozine. Table 2 shows the interrelations between uptake, the decrease in uptake caused by ferrozine and the level of ferri-reductase activity in each of the groups. In all groups the quantity of medium Fe chelated by ferrozine was less than $10 \%$ of the total. Both uptake and reductase activity was enhanced in hypoxic fasted animals. Two-way ANOVA showed

Table 2. Effect of $\mathrm{Fe}^{2+}$ chelation on $\mathrm{Fe}^{3+}$ uptake and ferri-reductase activity in duodenal fragments from rats $\dagger$

(Mean values with their standard errors for nos. of rats shown)

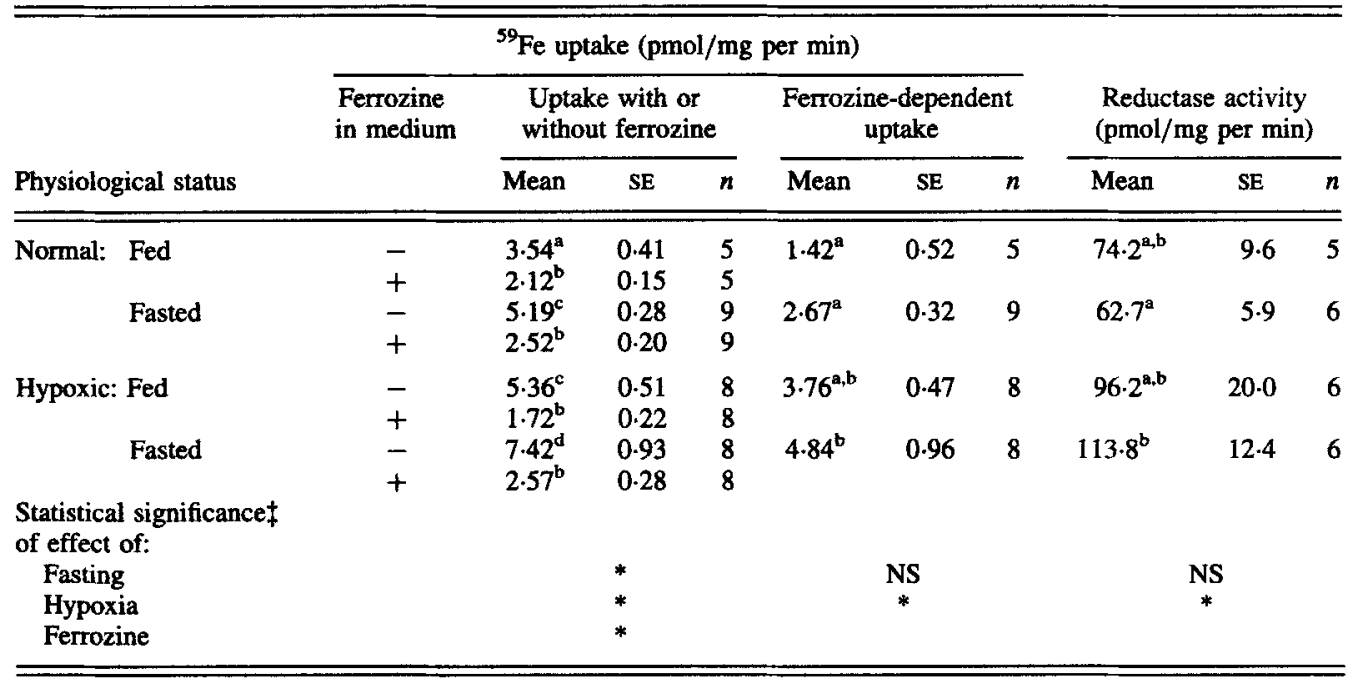

a,b,c Mean values in columns with unlike superscript letters were significantly different $(P<0.05)$.

- , Absent; + , present.

$* P<0.05$.

$\dagger$ For details of animals and procedures, see pp. 460-463.

IThe effect of fasting, hypoxia and ferrozine on Fe uptake was analysed by three-way ANOVA and the effect of fasting and hypoxia on ferrozine-dependent uptake and reductase activity by two-way ANOVA. 
that fasting had no significant effect on reductase activity, while hypoxia significantly increased reductase activity $(P<0.05)$.

\section{Mucosal free fatty acid levels}

There is evidence to suggest that free fatty acids could play a role in the facilitated transport of Fe across the mucosal brush border (Simpson et al. 1989). The effect of fasting on the response of $\mathrm{Fe}^{3+}$ uptake may be due to some change in the levels of free fatty acids in the rat brush-border membrane; therefore, the effect of fasting on free fatty acid levels in mucosa was investigated. There was rapid, linear production of free fatty acids in mucosal scrapings between 0 and $30 \mathrm{~min}$ after which production proceeded slowly, if at all. Twoway ANOVA showed that there was no difference in the rate of production (fed 26 (SE 4); $n 4 v$. fasted 30 (SE 3); $n 4 \mathrm{pmol} / \mathrm{min}$ per $\mathrm{mg}$ protein) of free fatty acids by mucosa from fed or fasted animals, in the magnitude of production nor in initial levels (fed 0.17 (SE 0.05 ); $n 4 v$. fasted 0.15 (SE 0.03 ); $n 4 \mu \mathrm{mol} / \mathrm{mg}$ protein). This suggests that mucosal fatty acids may not be important in the adaptive effect of fasting on Fe uptake mechanisms. Note, however, that local changes in fatty acid levels in the brush-border membrane could not be investigated by this technique.

\section{DISCUSSION}

In mice, the predominant mechanism involved in duodenal $\mathrm{Fe}^{3+}$ uptake is a saturable process which is dependent on metabolic energy (Raja et al. 1987b). The active uptake of $\mathrm{Fe}^{3+}$ in mice is also dependent on the membrane potential across the brush border and is enhanced in hypoxia (Raja et al. 1989). The latter two characteristics are useful markers for the carrier-mediated uptake of $\mathrm{Fe}^{3+}$ in mice and, since the rat is the most common animal model used in Fe nutrition studies, it was of interest to investigate the response of $\mathrm{Fe}^{3+}$ uptake by rat duodenal fragments to hypoxia and to membrane depolarization by incubation in high- $\mathrm{K}^{+}$solutions.

The data presented here demonstrated several differences in duodenal fragment $\mathrm{Fe}$ uptake between mice and rats, i.e. higher serosal uptake in rats (cf. Raja et al. 1987a), no effect of $\mathrm{Ca}^{2+}$ (cf. Raja et al. 1987c) or glucose omission (cf. Raja et al. 1992), a significant change in $K_{m}$ for uptake in hypoxia (cf. Raja et al. 1987a), in normoxic fed animals $\mathrm{Fe}^{3+}$ uptake was not inhibited by membrane depolarization and hypoxia had little effect in fed animals, in contrast to mice (Raja et al. 1987a, 1989, 1992). It has been reported that some mouse strains fail to exhibit increased in vivo Fe absorption after $3 \mathrm{~d}$ hypoxia (Simpson, 1992). This finding was related to rapidly increased haemoglobin levels. The present data indicate that this was not a factor in the rat (Table 1).

On the other hand, uptake by rat duodenum does show a dependence on medium oxygenation, as occurs in the mouse (Raja et al. 1992). When fed rats were exposed to $3 \mathrm{~d}$ of hypoxia the uptake was inhibited by membrane depolarization (30\%). When animals were fasted, uptake inhibition by membrane depolarization and induction by hypoxia were evident. It is possible, therefore, that the differences between the mice and rats may be partly explained by differences in food consumption over the $3 \mathrm{~d}$ of hypoxic exposure.

Previous studies of the effect of fasting on Fe absorption have given contradictory results. Osterloh et al. (1987) demonstrated reduced in vivo absorption of Fe in semistarved rats, while O'Riordan et al. (1994) observed increased absorption in overnight fasted rats. Murray \& Stein (1967) observed a decrease in in vitro Fe uptake in $18 \mathrm{~h}$ fasted rats. It is noteworthy, however, that no effect of semi-starvation or fasting on $\mathrm{Fe}^{3+}$ absorption has been observed by us in mice (Raja et al. 1988; R. J. Simpson and K. B. Raja, 
unpublished results). Earlier studies of the effect of fasting on Fe absorption are complicated by the presence of diet in the intestinal lumen of fed animals (Forrester et al. 1962; Donati et al. 1964; Conrad et al. 1967). Some of the contradictions noted previously may be explained by variations in the duration of fasting (Forrester et al. 1962). In our study, the use of in vitro incubated tissue fragments enables the mucosal effects of fasting to be observed, free from the direct effects of diet itself. We find that fasting induces a membrane-potential-sensitive Fe uptake mechanism with a low $K_{m}$. This is consistent with the findings of Debnam \& Thompson (1984) who reported that fasting induces an increased brush-border-membrane potential in the rat. Hypoxia also increases this mechanism of $\mathrm{Fe}$ uptake. The in vitro uptake observations are complicated by the presence of other uptake mechanisms, however, such that fasting alone has no significant effect on uptake by tissue from non-hypoxic rats at high medium-Fe concentrations $(450 \mu \mathrm{M})$.

An important consideration is whether fasting or hypoxia might influence $\mathrm{Fe}$ absorption by an effect on mucosal Fe or by an effect similar to low-Fe-diet feeding (Fairweather-Tait \& Wright, 1984; Schümann et al. 1989). Such studies generally show that low dietary Fe intakes increase Fe absorption, although it takes 2-3 d to produce a significant increase (Pearson et al. 1967). We have shown that the increased Fe absorption induced by hypoxia is not associated with a change in mucosal Fe level (Raja et al. 1987a) and that hypoxia and dietary Fe levels act independently to affect Fe absorption in mice (Simpson, 1996). It is noteworthy that the rats employed in the present study ate normally over the last $2 \mathrm{~d}$ of hypoxic exposure. Further investigation of the possible effect of fasting on mucosal Fe levels is necessary.

The importance of the present findings is the demonstration that the overall effect of a single perturbation on $\mathrm{Fe}$ uptake can be complicated by other factors which affect $\mathrm{Fe}$ absorption, thus the effect of hypoxia or fasting alone on Fe uptake depends on the status of the rats with regard to the other perturbation. Several physiological factors are known to affect Fe absorption, including dietary Fe levels, fasting, body Fe stores, erythropoietic rate, pregnancy, hypoxia and inflammation (Turnbull, 1974). Only limited data are available on interactions between these factors (Bothwell et al. 1958; Murray \& Stein, 1972; Batey \& Gallacher, 1977; Flanagan et al. 1980; Southon et al. 1989; Schümann et al. 1989, 1990; Raja et al. 1990), therefore the effect of a single factor on Fe absorption cannot always be predicted.

We further investigated the possible involvement of reported mechanisms of $\mathrm{Fe}$ uptake, i.e. free fatty acids (Simpson et al. 1989) and reduction-dependent processes. No evidence in support of an effect of fasting on total mucosal free fatty acid levels was observed. It should be noted, however, that previous studies have noted decreased brushborder-membrane fatty acids in fasted mice (Simpson et al. 1989) and rats (Alcorn et al. 1991). The sensitivity of $\mathrm{Fe}$ uptake to the $\mathrm{Fe}^{2+}$ chelator ferrozine is greatest in tissue from fasted hypoxic rats, consistent with the induction of an uptake mechanism dependent on reduction of $\mathrm{Fe}^{3+}$ to $\mathrm{Fe}^{2+}$, as proposed by Raja et al. (1992).

The reduction of $\mathrm{Fe}^{3+}$ ions to $\mathrm{Fe}^{2+}$ has been implicated as a key step in cellular $\mathrm{Fe}$ uptake processes in a variety of systems (Bienfait, 1985; Dancis et al. 1992; Raja et al. 1992; Hodgson et al. 1994; Nunez et al. 1994). In the case of intestinal Fe absorption, the uptake of Fe by the duodenum has been suggested to require a rate-determining reduction either in the intestinal lumen (Wollenberg \& Rummel, 1987; Barrand et al. 1990; Wien \& Van Campen, 1991), or at the mucosal surface. We have demonstrated that a mucosal surface reductase is present on mouse duodenum and that this reductase is regulated, in parallel with Fe uptake, by hypoxia and Fe deficiency (Raja et al. 1992). Others have recently failed to demonstrate regulation of mucosal reductase in isolated brush-border 
membranes from Fe-deficient rat duodenum (Wien \& Van Campen, 1994), however, studies of isolated membranes may lack an important regulatory factor.

The present data implicate a mucosal surface reductase in the uptake of Fe by the rat duodenum. This reductase is observed in intact tissue incubated in physiological medium. The findings further demonstrate that $\mathrm{Fe}$ uptake by rat duodenum involves a low $K_{m}$ mechanism which depends on an intact membrane potential. Other mechanisms of uptake are implicated, particularly in normoxic fed animals. These observations show similarities to findings made with human duodenum (Raja et al. 1996; K. B. Raja, unpublished results). This provides support for the use of rats as a model for human Fe absorption. It should be noted, however, that the presence of multiple uptake mechanisms which show independent responses to physiological modulations such as fasting, means that extrapolation from one species to another requires caution, particularly at the present stage, where we remain ignorant of the relative importance of these various mechanisms for Fe nutrition in the various species.

We thank Dr D. J. Pountney for assistance with Fe uptake and reduction assays and Dr T. Mayall for communications support. E.M.T. was supported by a Wellcome Trust Prize Studentship. This is a contribution from the King's College Centre for the Study of Metals in Biology and Medicine.

\section{REFERENCES}

Alcorn, C. J., Simpson, R. J., Leahy, D. \& Peters, T. J. (1991). In vitro studies of intestinal drug absorption. Determination of partition and distribution coefficients with bush border membrane vesicles. Biochemical Pharmacology 42, 2259-2264.

Barrand, M. A., Hider, R. C. \& Callingham, B. A. (1990). The importance of reductive mechanisms for intestinal uptake from ferric maltol and ferric nitrilotriacetic acid (NTA). Journal of Pharmacy and Pharmacology 42 , 279-282.

Batey, R. \& Gallacher, N. (1977). Effect of iron stores and hysterectomy on iron absorption and distribution in pregnant mice. American Journal of Physiology 232, E57-E61.

Bienfait, H. F. (1985). Regulated redox processes at the plasmalemma of plant-root cells and their function in iron uptake. Journal of Bioenergetics and Biomembranes 17, 73-83.

Bihler, I. \& Crane, R. K. (1962). Studies on the mechanism of intestinal absorption of sugars. V. Influence of several cations and anions on the active transport of sugars in vitro by various preparations of hamster small intestine. Biochimica et Biophysica Acta 59, 78-93.

Bothwell, T. H., Pirzio-Biroli, G. \& Finch, C. A. (1958). Iron absorption. I. Factors influencing absorption. Journal of Laboratory and Clinical Medicine 51, 24-36.

Conrad, M. E., Foy, A. L., Williams, H. L. \& Knospe, W. H. (1967). Effect of starvation and protein depletion on ferrokinetics and iron absorption. American Journal of Physiology 213, 557-565.

Cox, T. M. \& Peters, T. J. (1979). Cellular mechanisms in the regulation of iron absorption: studies in deficiency before and after treatment. Journal of Physiology 289, 469-478.

Cox, T. M. \& Peters, T. J. (1980). In vitro studies of duodenal iron uptake in patients with primary and secondary iron storage disease. Quarterly Joumal of Medicine 49, 249-257.

Dancis, A., Roman, D. G., Anderson, G. J., Hinnesbusch, A. G. \& Klausner, R. D. (1992). Ferric reductase of Saccharomyces cerevisiae: molecular characterisation, role in iron uptake, and transcriptional control by iron. Proceedings of the National Academy of Sciences USA 89, 3869-3873.

Debnam, E. S. \& Thompson, C. S. (1984). The effect of fasting on the potential difference across the brushborder membrane of enterocytes in rat small intestine. Journal of Physiology 355, 449-456.

Donati, R. M., Chapman, C. W., Warnecke, M. A. \& Gallacher, N. I. (1964). Iron metabolism in acute starvation. Proceedings of the Society for Experimental Biology and Medicine 117, 50-53.

Drabkin, D. L. \& Austin, J. H. (1932). Spectrophotometric studies. I. Spectrophotometric constants for common haemoglobin derivatives in human, dog and rabbit blood. Joumal of Biological Chemistry 98, 719-733.

Eisenthal, R. \& Cornish-Bowden, A. (1974). The direct linear plot. A new graphical procedure for estimating enzyme kinetic parameters. Biochemical Journal 139, 715-720.

Fairweather-Tait, S. J. \& Wright, A. J. A. (1984). The influence of previous iron intake on the estimation of bioavailability of Fe from a test meal given to rats. British Journal of Nutrition 51, 185-191. 
Falholt, K., Lund, B. \& Falholt, W. (1973). An easy colorimetric micromethod for routine determination of free fatty acids in plasma. Clinica Chimica Acta 46, 105-111.

Flanagan, P. R., Haist, J. \& Valberg, L. S. (1980). Comparative effects of iron deficiency induced by bleeding and a low-iron diet on the intestinal absorptive interactions of iron, cobalt, manganese, zinc, lead and cadmium. Journal of Nutrition 110, $1754-1763$.

Forrester, R. H., Conrad, M. E. \& Crosby, W. H. (1962). Measurement of total body iron59 in animals using whole body liquid scintillation detectors. Proceedings of the Society for Experimental Biology and Medicine 111, 115-119.

Foy, A. L., Williams, H. L., Cortell, S. \& Conrad, M. E. (1967). A modified procedure for the determination of non heme iron in tissue. Analytical Biochemistry 18, 559-563.

Glantz, S. A. \& Slinker, B. K. (1990). Primer of Applied Regression and Analysis of Variance. New York: McGraw-Hill Inc.

Hodgson, L. L., Quail, E. A. \& Morgan, E. H. (1994). Receptor-independent uptake of transferrin-bound iron by reticulocytes. Archives of Biochemistry and Biophysics 308, 318-326.

Minitab Inc. (1992). Minitab Version 7.2. Philadelphia, PA: State College.

Murray, M. J. \& Stein, N. (1967). Effects of intestinal contents on uptake of radioiron by everted rat gut sacs. Proceedings of the Society for Experimental Biology and Medicine 125, 411-413.

Murray, M. J. \& Stein, N. (1972). The effect of injected iron on the absorption of iron in iron deficiency. British Journal of Haematology 23, 13-16.

Nunez, M. T., Alvarez, X., Smith, M., Tapia, V. \& Glass, J. (1994). Role of redox systems on Fe ${ }^{3+}$ uptake by transformed human intestinal epithelial (Caco-2) cells. American Journal of Physiology 267, C1582-C1588.

O'Riordan, D. K., Sharp, P. A., Epstein, O., Srai, S. K. S. \& Debnam, E. S. (1994). Increased iron transfer in overnight fasted rats. Gut 35, S52.

Osterloh, K. R. S., Simpson, R. J., Snape, S. \& Peters, T. J. (1987). Intestinal iron absorption and mucosal transferrin in rats subjected to hypoxia. Blut 55, $421-431$.

Pearson, W. N., Reich, M., Frank, H. \& Salamat, L. (1967). Effect of dietary iron level on gut iron levels and iron absorption in the rat. Joumal of Nutrition 92, 53-65.

Raja, K. B., Bjarnason, I., Simpson, R. J. \& Peters, T. J. (1987a). In vitro measurement and adaptive response of $\mathrm{Fe}^{3+}$ uptake by mouse intestine. Cell Biochemistry and Function 5, 69-76.

Raja, K. B., Duane, P. E., Ward, R. J., Iancu, T. C., Simpson, R. J. \& Peters, T. J. (1990). In vitro and in vivo studies on $\mathrm{Fe}^{3+}$ absorption by mouse duodenum. Effect of iron loading on adaptive response to chronic hypoxia. Biochemical Pharmacology 9, 107-117.

Raja, K. B., Pountney, D. J., Bomford, A., Przemioslo, R., Sherman, D., Simpson, R. J., Williams, R. \& Peters, T. J. (1996). A duodenal mucosal abnormality in the reduction of Fe(III) in patients with genetic haemochromatosis. Gut 38, 765-769.

Raja, K. B., Simpson, R. J. \& Peters, T. J. (1987b). Comparison of ${ }^{59} \mathrm{Fe}^{3+}$ uptake in vitro and in vivo by mouse duodenum. Biochimica et Biophysica Acta 901, 52-60.

Raja, K. B., Simpson, R. J. \& Peters, T. J. (1987c). Effect of $\mathrm{Ca}^{2+}$ and $\mathrm{Mg}^{2+}$ on the uptake of Fe intestinal mucosa. Biochimica et Biophysica Acta 923, 46-51.

Raja, K. B., Simpson, R. J. \& Peters, T. J. (1989). Membrane potential dependence of Fe(III) uptake by mouse duodenum. Biochimica et Biophysica Acta 984, 262-266.

Raja, K. B., Simpson, R. J. \& Peters, T. J. (1992). Investigation of a role for reduction in ferric iron uptake by mouse duodenum. Biochimica et Biophysica Acta 1135, 141-146.

Raja, K. B., Simpson, R. J., Pippard, M. J. \& Peters, T. J. (1988). In vivo studies on the relationship between intestinal iron $\left(\mathrm{Fe}^{3+}\right.$ ) absorption, hypoxia and erythropoiesis in the mouse. British Journal of Haematology 68 , 373-378.

Schümann, K., Elsenhans, B., Ehtechami, C. \& Forth, W. (1990). Increased intestinal iron absorption in rats with normal hepatic iron stores. Kinetic aspects of the adaptive response to parenteral iron repletion in dietary iron deficiency. Biochimica et Biophysica Acta 1033, 277-281.

Schümann, K., Elsenhans, B., Hunder, G., Strugala, G. \& Forth, W. (1989). Increase of the intestinal iron absorption in growing rats and mice after 8 days of iron-deficient feeding. Zeitschrift fuir Versuchstierkunde 32, 261-267.

Simpson, R. J. (1992). Effect of hypoxic exposure on iron absorption in heterozygous hypotransferrinaemic mice. Annals of Haematology 65, 260-264.

Simpson, R. J. (1996). Dietary iron levels and hypoxia independently affect iron absorption in mice. Journal of Nutrition 126, 1858-1864.

Simpson, R. J., Venkatesan, S. \& Peters, T. J. (1989). Brush border membrane non-esterified fatty acids. Physiological levels and significance for mucosal iron uptake in mouse proximal intestine. Cell Biochemistry and Function 7, 165-171.

Southon, S., Wright, A. J. \& Fairweather-Tait, S. J. (1989). The effect of differences in dietary iron intake on ${ }^{59} \mathrm{Fe}$ absorption and duodenal morphology in pregnant rats. British Journal of Nutrition 62, 707-717.

Turnbull, A. (1974). Iron absorption. In Iron in Biochemistry and Medicine, pp. 369-402 [A. Jacobs and M. Worwood, editors]. London: Academic Press. 
Wien, E. M. \& Van Campen, D. R. (1991). Ferric iron absorption in rats: relationship to iron status, endogenous sulfhydryl and other redox components in the intestinal lumen. Journal of Nutrition 121, 825-831.

Wien, E. M. \& Van Campen, D. R. (1994). Enhanced $\mathrm{Fe}^{3+}$-reducing capacity does not seem to play a major role in increasing iron absorption in iron-deficient rats. Journal of Nutrition 124, 2006-2015.

Wollenberg, P. \& Rummel, W. (1987). Dependence of intestinal iron absorption on the valency state of iron. Archives of Pharmacology 336, 578-582. 